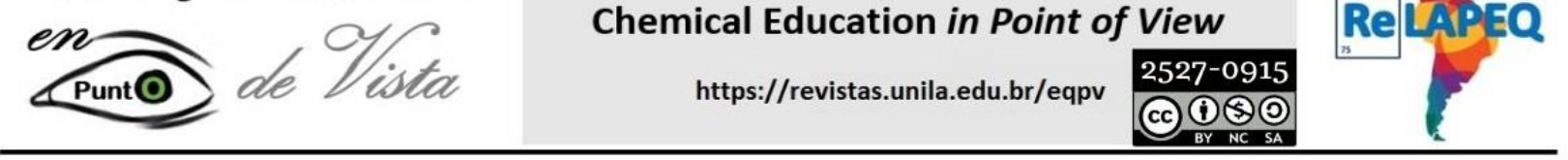

\title{
A tabela periódica em fascículos: uma proposta de objeto educacional
}

\author{
Mayana Ferreira da Cunha ${ }^{1}$, Thiago Henrique Barnabé Corrêa ${ }^{2}$ \\ ${ }^{1}$ Mestra em Química pela Universidade Federal do Triângulo Mineiro (UFTM/Brasil). \\ Professora de Química da Educação Básica. \\ ${ }^{2}$ Doutor em Ciências pela Universidade Estadual de Campinas. \\ Professor do Programa de Mestrado Profissional em Química em Rede Nacional - PROFQUI/UFTM.
}

The periodic table in fascicles: a proposal for an educational object

Informações do Artigo

Recebido: 02/07/2020

Aceito: $19 / 12 / 2020$

Palavras chave:

ensino de química; classificação periódica; história da ciência.

Key words:

chemistry teaching; periodic

classification; history of science.

\begin{abstract}
A B S T R A C T
This article presents a study that investigated the potential of a didactic-pedagogical proposal (e-book) for Chemistry teachers and high school students, which was designed and developed with the aim of being versatile and that promotes, from a fluid language, a dialogue with the readers, so that they can explore the chemical concepts that deal with the content of the periodic table. It is important to note that there is no intention to replace textbooks, but rather to be a complementary and easily accessible educational resource, through digital or printed media (binder).
\end{abstract}

E-mail: mayanafcunha@gmail.com

\section{INTRODUÇÃO}

Dentre os conteúdos químicos que merece destaque e que, habitualmente, vem sendo ensinado sob a ótica da memorização, está o da tabela periódica (TP). Para Penteado, Oliveira e Zacharias (2010), o aprendizado sobre a TP é um caso bem particular do ensino tradicional de Química, no qual os alunos, por vezes, deparam-se com a árdua tarefa de ter que decorar os nomes dos elementos químicos e as propriedades periódicas, tornando este processo muito cansativo e massacrante.

Como pontuam Trassi et al. (2001) e Leite et al. (2006), o ensino atual da tabela periódica privilegia aspectos teóricos de forma complexa, uma vez que é um dos temas que mais apresenta problemas para a aprendizagem dos alunos devido a sua natureza abstrata. De acordo com Berbaum e Maldaner (2016):

A Tabela Periódica (TP) é um instrumento utilizado na consulta e previsão de um grande número de propriedades químicas dos elementos. É chamada 
de periódica porque mostra a repetição de algumas propriedades que determinados elementos têm em comum. No entanto, pesquisas relatam que ela vem sendo utilizada por estudantes do Ensino Médio apenas como fonte de consulta de dados e informações numéricas, ficando esquecida sua questão central, que é a periodicidade dos elementos químicos (BERBAUM; MALDANER, 2016, p. 1).

Indubitavelmente, a TP é uma das mais brilhantes construções científicas e seu amplo entendimento é de suma importância para o ensino de Química, visto que, permite ao aluno desenvolver uma lógica de pensamento químico, proporcionando uma interface com os demais conteúdos químicos, garantindo aporte para que os professores trabalhem outros conceitos.

Além disso, a tabela periódica é uma valiosa ferramenta didática no ensino de Química, presente desde a sala de aula aos mais avançados centros de pesquisa, que contribuiu para a sistematização e organização do conhecimento científico, tornando-se um ícone da Química. Vale destacar que, em 2019, foi celebrado o Ano Internacional da Tabela Periódica, visando reconhecer sua importância como uma das construções científicas mais relevantes da ciência moderna.

Nesse contexto, a Assembleia Geral da ONU e a Unesco (2019) descreveu a data como uma oportunidade para se refletir sobre os diversos aspectos que circundam a tabela periódica, incluindo sua história, o papel das mulheres na pesquisa científica, as tendências e as perspectivas mundiais sobre a ciência para o desenvolvimento sustentável, além de seus impactos sociais e econômicos. Além do exposto, a comemoração do ano internacional da TP faz uma menção aos 150 anos da publicação do primeiro esboço da tabela periódica contendo 63 elementos químicos, em 1ㅇ de março de 1869, do notável químico russo Dmitri Mendeleiev (1834 - 1907). Mendeleiev decidiu usar o formato de um jogo de cartas para organizar os elementos químicos da TP, com isso, ele pegou várias fichas de papel e começou a escrever em cada uma delas o nome de um elemento, acompanhado de sua massa atômica e propriedades químicas.

Embora a construção da TP tenha tido a participação de diversos estudiosos, o protagonismo de Mendeleiev se deve ao fato de ter previsionado a existência de elementos, até então, desconhecidos na época, tais como o gálio, o germânio e o escândio. Conforme sinalizam Kotz, Treichel e Weaver (2012), as previsões de Mendeleiev se tornaram ainda mais brilhantes quando foram confirmadas com a descoberta do germânio em 1886; além das propriedades químicas e físicas semelhantes aos elementos pertencentes à mesma coluna.

Conforme traz Strathern (2002, p. 251), Mendeleiev classificou os tijolos do universo, assim, "como os axiomas da geometria, da física newtoniana e da biologia darwiniana, a 
Química tinha agora uma ideia central sobre a qual todo um novo corpo de ciência podia ser construído".

Mesmo diante de tal relevância, sabe-se que o ensino da TP é, em alguns casos, tratado no ensino médio sob uma abordagem superficial, anacrônica e descontextualizada. A respeito de tal proposição, é necessário refletir sobre os desafios e obstáculos presentes no ensino de Química, os quais influenciam a construção do conhecimento científico, a prática e a formação docente, norteando a seguinte questão: Como contribuir para uma aprendizagem relevante da tabela periódica no ensino de Química?

Frente ao atual contexto escolar em que o ensino de Química está inserido, torna-se importante refletir as estratégias de ensino adotadas pelos docentes, assim como, ressignificar as práticas pedagógicas de forma que torne o ensino desta Ciência mais atrativo e relevante.

Como se sabe, os professores de Química encontram dificuldades em ensinar a TP a seus alunos, o que segundo Ferreira, Correa e Dutra (2016) pode estar relacionada à falta de clareza em relação aos seus objetivos. Não obstante, é sabido que os desafios no ensino da Tabela Periódica em nível médio são reflexos de uma deficiência identificada desde a prática de ensino, geralmente permeada por uma abordagem tradicional inserida nos cursos de licenciatura aos materiais didáticos utilizados

Diante do exposto, César, Reis e Aliane (2015) destacam que durante a formação inicial do professor de Química, há livros didáticos do ensino superior que fornecem uma concepção da TP como um produto pronto e que depende do entendimento da teoria atômica moderna, sem considerar o movimento contrário. Esses mesmos livros muitas das vezes ignoram que ao longo dos anos, a TP resultou da colaboração de vários personagens em diferentes contextos, passando por muitas transformações que reforçaram, e ainda reforçam, que a Química não é um conhecimento absoluto e imutável.

Embora a TP seja apresentada no ensino de Química, sobretudo no ensino médio, vale dizer que ela não apresenta uma natureza pedagógica, pois sua criação e proposição não tem como finalidade facilitar o processo de ensino e aprendizagem. Porém, isso não impede considerar que a TP tenha uma dimensão pedagógica, ou seja, a potencialidade de ser um instrumento didático capaz de contribuir para o entendimento do conteúdo químico que se pretende explorar (CUNHA, 2019).

Portanto, frente às lacunas no ensino da tabela periódica, este artigo traz o trabalho desenvolvido no âmbito do Mestrado Profissional em Química em Rede Nacional (PROFQUI) com a elaboração de uma proposta didático-pedagógica destinada à professores de Química e alunos do ensino médio. A referida proposta não exclui a importância do livro didático, mas visa atender as necessidades dos docentes, de forma a potencializar a prática na sala de aula e contribuir para a compreensão deste estudo, proporcionando, a partir de uma 


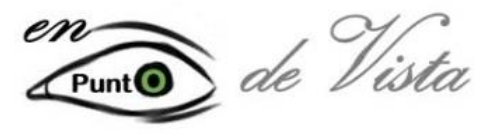

linguagem fluída, uma interlocução com os leitores de modo que estes possam explorar os conceitos químicos que versam o conteúdo da tabela periódica.

A escolha deste tema se justifica pelo fato de que a tabela periódica apresenta uma riqueza de informações e atua como um instrumento facilitador na compreensão de diversos conceitos químicos. Em outras palavras, a tabela periódica é um elo de comunicação que permite ao aluno perceber a inter-relação dos conceitos químicos.

\section{APORTES METODOLÓGICOS}

Para o desenvolvimento metodológico e com o propósito de responder à questão norteadora, delineou-se uma pesquisa com abordagem qualitativa, a qual foi constituída por três etapas, sendo duas de análise e uma intermediária. Na primeira etapa de análise, foi realizado um estudo dos indicadores sobre o ensino da tabela periódica. Na segunda, foi aplicado um questionário a fim de verificar as potencialidades desse material na prática pedagógica. Já, na etapa intermediária, houve o desenvolvimento de um objeto educacional no formato de e-book, a partir das lacunas identificadas na primeira etapa da análise.

Com o propósito de subsidiar o conteúdo do material e nortear o trabalho identificando as lacunas no ensino da tabela periódica, na primeira etapa da pesquisa foi realizada uma entrevista semiestruturada, com quatro sujeitos da pesquisa, os quais representam a totalidade dos professores da rede pública de ensino em Uberaba-MG, mediante a devida anuência dos mesmos, por meio do Termo de Consentimento Livre e Esclarecido. A fim de preservar a imagem e a privacidade dos participantes, foram outorgadas menções fictícias aos mesmos: $s, \boldsymbol{p}, \boldsymbol{d}, \boldsymbol{f}$. Curiosamente, todos apresentam mais de cinco anos de efetivo exercício na docência, conforme está explicitado a seguir (Tabela 1).

Tabela 1. Informações referentes à formação docente dos professores participantes.

\begin{tabular}{|l|l|c|}
\hline & \multicolumn{1}{|c|}{ FORMAÇÃO ACADÊMICA } & TEMPO DE MAGISTÉRIO \\
\hline Professora $\boldsymbol{s}$ & Licenciatura em Química (UNIUBE). & 10 anos \\
\hline Professora $\boldsymbol{p}$ & $\begin{array}{l}\text { Licenciatura em Química, Engenharia } \\
\text { Química (FAENQUIL/USP) e } \\
\text { Especialização na área educacional e } \\
\text { ambiental. }\end{array}$ & 22 anos \\
\hline Professor $\boldsymbol{d}$ & $\begin{array}{l}\text { Licenciatura em Química (UNIUBE) e } \\
\text { Mestrado em Química (UFU). }\end{array}$ & 12 anos \\
\hline Professor $\boldsymbol{f}$ & $\begin{array}{l}\text { Licenciatura em Química (IFTM) e } \\
\text { Mestrado em Química (UFTM). }\end{array}$ & 12 anos \\
\hline
\end{tabular}

Fonte: Própria autoria. 


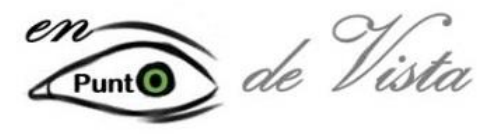

Diante disso, as entrevistas semiestruturadas realizadas a partir de um roteiro préestabelecido (Apêndice 1) contemplaram seis perguntas que foram exploradas de acordo com a designação de duas categorias de análise classificadas em: 1â) Concepção dos professores quanto ao ensino da tabela periódica; e, 2ª) Aspectos da prática pedagógica.

Nesse trabalho, buscou-se priorizar a informação química em versão de texto de apoio que, posteriormente, foi organizada em um formato de e-book (objeto educacional), contemplando 32 fascículos norteadores, sendo 27 centrais e 5 complementares, o qual tem como caraterística o emprego de algumas perguntas e tópicos que incitem a exploração do conteúdo sobre a classificação periódica dos elementos sem a necessidade de decorá-lo.

Dentre os diversos temas abordados, podem ser destacados a origem dos elementos; aspectos históricos; o conceito de elementos através dos tempos; as mulheres na Ciência; a descoberta do lítio e sua relação com o Brasil; as diferentes formas de representação da tabela periódica e suas organizações; as tríades de Döbereiner; e, a relação entre as propriedades (a)periódicas dos elementos e outros conteúdos químicos (Figura 1).

Figura 1 - Fascículos elaborados no objeto educacional (e-book).
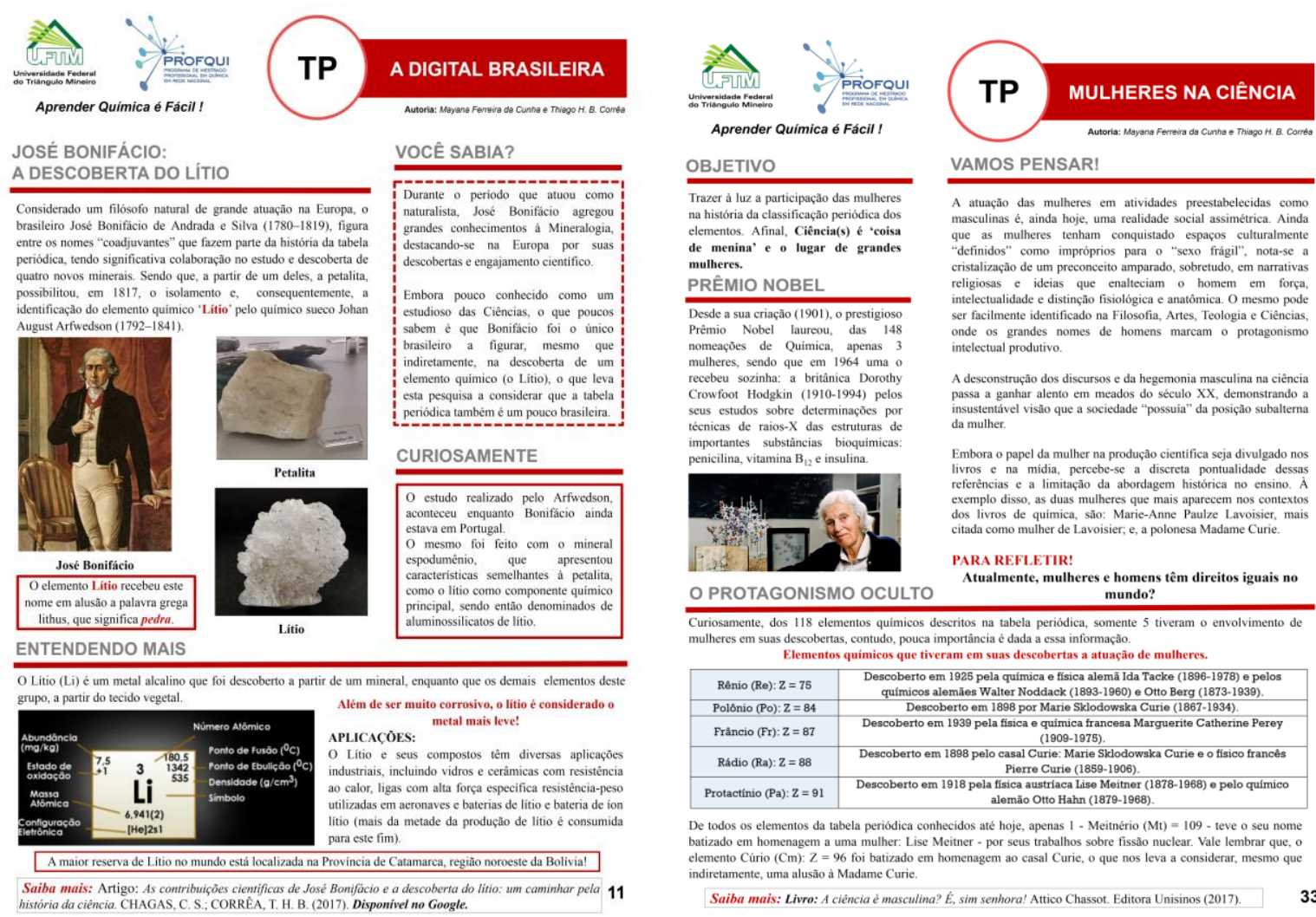

Fonte: Própria autoria. 

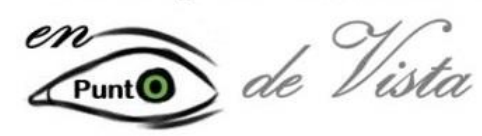

Chemical Education in Point of View

2527-0915

https://revistas.unila.edu.br/eqpv

No corpo do material elaborado, algumas perguntas foram empregadas na qualidade de catalisadores para a imersão do sujeito, tornando-as elementos motivacionais e fundamentais para o despertar da curiosidade. Para isso, atribuiu-se um estilo lingüístico (de escrita) contextualizado, de modo a conduzir o aluno a refletir sobre os tópicos sintetizados.

Assim, por meio da organização proposta, acredita-se que a apresentação dos conceitos no estudo da tabela periódica obteve uma organização coesa e coerente, a qual visou atender os docentes no planejamento e aplicação desses tópicos no ensino médio, potencializando a prática pedagógica.

Pontua-se que o material desenvolvido pode ser disponibilizado tanto no formato de um e-book - considerando a praticidade dos alunos em carregá-lo em seus dispositivos móveis - como, também, impresso, possibilitando a revisitação na articulação com futuros conteúdos químicos tratados pelos professores.

É importante salientar que a segunda etapa foi pautada em um questionário semiaberto contemplando sete perguntas, com o caráter de validação do objeto educacional desenvolvido a partir das lacunas no ensino da tabela periódica identificadas nas entrevistas com participantes da pesquisa (Apêndice 2). Em seguida, o questionário e o e-book foram disponibilizados para os mesmos, os quais tiveram por um período pré-estabelecido de quinze a vinte dias, a oportunidade de conhecer o material e responder ao questionário.

A dissertação intitulada "A dimensão pedagógica da Tabela Periódica no ensino de conceitos químicos" e o e-book batizado de "CLASSIFICAÇÃO PERIÓDICA DOS ELEMENTOS A TABELA COMO VOCÊ NUNCA VIU!", - devidamente registrado no portal eduCAPES (https://educapes.capes.gov.br/handle/capes/574403) - estão, também, disponíveis no site da Universidade Federal do Triângulo Mineiro (UFTM) e do Programa de Mestrado Profissional em Química em Rede Nacional (PROFQUI).

Embora a publicação do produto educacional seja recente (2019), pontua-se que até a presente data (dezembro de 2020), a plataforma eduCAPES registrou visualizações do referido trabalho em países como Estados Unidos, Irlanda e Colômbia.

\section{RESULTADOS E DISCUSSÕES}

\section{- O e-book como aporte didático}

A partir das lacunas identificadas no ensino da tabela periódica na primeira etapa da referida pesquisa, foi possível a elaboração de um objeto educacional (e-book). Mesmo que as respostas dos professores tenham indicado para a concordância quanto à importância do ensino da TP e sua íntima relação com os demais conteúdos da Química, foi possível perceber que em diversos momentos, os entrevistados apontam as dificuldades de tornar o ensino de Química mais atrativo. 
No que se refere à maneira como exploram a história da ciência quando abordam o conteúdo da tabela periódica, os participantes da pesquisa não hesitaram em dizer que, geralmente, não apresentam os aspectos históricos e quando há essa abordagem é, extremamente, superficial. De modo que, não comprometa o ensino da tabela periódica em sua totalidade.

O principal motivo dessa "superficialidade" com relação ao período histórico, apontado pelos entrevistados, deve-se à reduzida quantidade de aulas de Química no ensino médio. Especificamente, na rede pública de ensino são 2 (duas) aulas semanais.

De fato, a quantidade de aulas pode influenciar no cumprimento do planejamento anual e grade curricular dos alunos, todavia, não está relacionada à qualidade do ensino da tabela periódica. Visto que, a história dessa construção científica é de fundamental importância para o entendimento da periodicidade e demais conceitos químicos que versam o conteúdo da TP.

De acordo com os relatos dos professores, a seguir:

(...) como o tempo é pequeno, curto, eu estou falando, assim para gente lecionar mesmo... Geralmente, a gente nem fala muito, a gente já entra direto na tabela, eu, pelo menos, trabalho dessa forma. Pelo tempo estar curto, pela correria do ano, né, eu já entro explicando um pouquinho sobre o Mendeleev ali, oh, organização e tudo, né, falando que foi organizado em ordem crescente de número atômico e tudo. Não fico, não fico entrando muito em história não, eu tô falo assim, pelo tempo corrido, né. Eu tô falando assim, tá, eu já entro realmente, assim, né, já explicando sobre a tabela, os períodos certinhos, as famílias, como que foi organizada, né... (Profós);

(...) Olha a "história" eu abordo muito pouco, porque são 2 aulas semanais, então, assim, a Química é um conteúdo extenso para 2 aulas. Então, já vai no básico do que o aluno precisa saber, o que é o principal que o aluno precisa saber da tabela periódica... Entendeu? E vou com a matéria, então a parte histórica é muito pouco, eu só falo, eu nem ponho no quadro, o resumo da história, entendeu. Só falo e ali vai... Então, essa parte, assim, como que chegou na tabela de hoje, é só falado. Quando eu vou entrar no capítulo eu falo como que organizou a tabela, as tríades, vou falando direitinho... Mas, assim, de pôr no caderno, falar para eles copiar, cobrar na prova isso daqui... Isso aí, não. (Prof $\underline{a}$ p);

(...) No começo, eu falava muito mais da questão histórica do que hoje. Hoje, ao invés de eu gastar o tempo falando historicamente, eu gasto o tempo tentando associar com o cotidiano do aluno. Porque eu não vou ter tempo para fazer os dois e, muitas vezes, em algumas situações quando eu cito exemplo da vivência dele, eu consigo uma atenção um pouco maior. (Prof. d);

Diante disso, foi possível verificar que a questão do "tempo" disponível foi relatado por diversos momentos, nas falas dos professores participantes como uma justificativa de não discutirem os aspectos históricos da tabela periódica. 

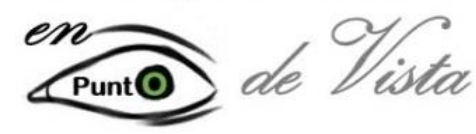

Chemical Education in Point of View

2527-0915

https://revistas.unila.edu.br/eqpv

No entanto, é de suma importância salientarmos que em concordância com Leite e Porto (2015), a história do desenvolvimento da tabela periódica, ao invés da simples menção a nomes e datas de "grandes descobertas", se houver a apresentação das contribuições de diversos cientistas, delineando a complexidade do processo de construção da ciência, possibilita o entendimento desta como uma construção coletiva e permanente. Sendo que, o processo histórico pode auxiliar o entendimento da periodicidade dos elementos e os raciocínios químicos que levaram à sua proposição.

Foi notório também que, apesar dos entrevistados alegarem discutir a configuração eletrônica dos elementos, para Berbaum e Maldaner (2016), no ensino de Química atual, a periodicidade dos elementos químicos fica omitida no desenvolvimento dos conteúdos referentes à tabela periódica.

Na segunda etapa de análise, com relação à qualidade das informações e conteúdo químico do material elaborado (e-book), houve uma similaridade nas concepções dos docentes, como pode ser exteriorizado nas falas a seguir:

\section{(...) O material ficou muito bom e criativo. (Prof $\left.{ }^{a} p\right)$;}

(...) O material engloba bastante conteúdo, fornecendo ao leitor meios de aprender o básico ou se tornar um expert no assunto, servindo o material para "iniciantes" ou "avançados" na química. (...) A utilização de imagens dá "uma cara" chamativa para o material, de forma a não cansar os olhos ou a mente durante a leitura. O material ainda traz informações bem "escondidas" nos livros, de forma que precisa ler vários materiais para tanta informação. Havia muitas coisas que eu não sabia, o que me deixou feliz ao ler. Me acrescentou bastante. A fundamentação teórica está bem completa. (Prof. $d$ );

Quanto à utilização do material desenvolvido nas aulas, todos os docentes participantes sinalizaram positivamente ao uso, conforme exposto nas alternativas (a) e (b) da questão 2, pela abrangência de conteúdo e organização objetiva do material e por acreditarem que despertaria interesse nos alunos. Da mesma maneira, houve uma concordância entre os professores $\boldsymbol{p}, \boldsymbol{d}$ e $\boldsymbol{f}$ na alternativa (c), quanto à carência de materiais com essa perspectiva. Em relação à alternativa $(d)$, os professores $p$ e $f$, reconheceram que o material complementa os livros didáticos.

No que se refere a questão 3, cujo objetivo foi identificar dentre os conteúdos abordados, qual mais chamou a atenção dos docentes e o porquê deles, a concepção destes evidencia a relevância desse material no ensino de Química e, particularmente, da tabela periódica. Conforme as falas a seguir:

(...) Gostei de todo o material. Ele é colorido, chama a atenção, linguagem de fácil entendimento. (Prof $\underline{a} p)$; 

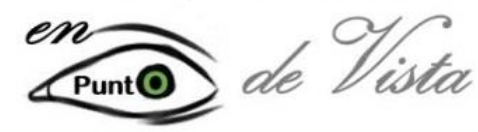

Chemical Education in Point of View

2527-0915

https://revistas.unila.edu.br/eqpv

(...) O que mais me chamou a atenção foi a preocupação de familiarizar os elementos químicos, fazendo com que não sejam somente símbolos com informações em um quadro. De forma geral, a preocupação em introduzir o conceito de maneira que o aluno consiga associar com outras coisas como sua vivência, a história e a outras matérias. (Prof. d);

As explanações dos participantes da pesquisa, quanto à principal potencialidade (aspecto positivo) do material, vão ao encontro das expectativas na elaboração deste objeto educacional. Conforme pode ser constatado nas seguintes falas, todos os professores enfatizaram a riqueza de informações, bem como a organização, apresentação e articulação das mesmas, proporcionando a "quebra de paradigma" presente no atual ensino da tabela periódica. Assim, dentre as respostas, destaca-se:

(...) A aspecto da contextualização, pois o material transmite informações suficiente para que o aluno elabore suas ideias de forma significativa. (Prof ${ }^{a} s$ );

(...) A primeira impressão é visual. As cores, fontes, organização dos títulos, destaques para principais conceitos, separação de ideias e a preocupação com a disposição das informações são muito positivos. Me surpreendeu bastante. Acredito isso irá colaborar pra uma leitura bem prazerosa. (Prof. d);

(...) O novo tipo de abordagem de um assunto bem conhecido e que é a base da química, a tabela periódica. Os alunos de nono ano, ao se depararem com esse tipo de material, criam um interesse imediato pela química, assim como os alunos de primeiro ano que tem um preconceito da forma como esse conteúdo foi abordado no 9o ano. (Prof. f);

Diante das colocações realizadas pelo professor $\boldsymbol{d}$, é extremamente relevante apontarmos algumas reflexões sobre o material elaborado. Primordialmente, apesar de haver uma dimensão pedagógica, o e-book não tem a finalidade de substituir os livros didáticos, mas, sim, de complementá-los.

No que diz respeito à maneira que os entrevistados identificam o conteúdo histórico do material quanto aos (precursores, a contribuição de José Bonifácio e as mulheres na Ciência), houve uma similaridade nas respostas dos professores $\boldsymbol{s}, \boldsymbol{d}$ e $\boldsymbol{f}$, classificando-o como excelente. Já, a professora $\boldsymbol{p}$ identificou-o como bom. No geral, todas as respostas foram consideradas positivas, o que vai ao encontro da nossa pretensão quanto ao material desenvolvido, isso devido à falta dessas discussões nos livros didáticos comumente adotados e, muitas vezes, por haver a carência de uma formação docente apropriada.

Quanto à concepção dos professores participantes, sobre como o material desenvolvido pode contribuir em suas aulas, assim como, no ensino dos conteúdos 

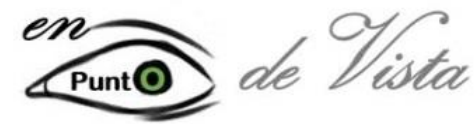

químicos, as respostas dos participantes, mais uma vez, nos surpreenderam com apontamentos tão relevantes e enaltecedores.

(...) Sim, pode contribuir, pois o material é extremamente motivacional, pois mostra diversas formas para proporcionar um ensino mais completo, divertido e interessante. (Prof ${ }^{a} s$ );

(...) Acho uma boa ideia um e-book deste material. Pois é um material bem completo. Para finalizar, os conceitos e conteúdos abordados englobam ideias de vários autores, enriquecendo o conteúdo apresentado, o que fornece meios para que o aluno seja competitivo também no meio de vestibulares e outros. (Prof. d);

Sendo assim, diante dos argumentos externados pelos sujeitos da pesquisa, conforme o questionário disponibilizado e a fim de verificar as potencialidades do objeto educacional elaborado na presente dissertação, foi notória a importância desse produto (ebook) não só para o ensino da tabela periódica, mas também, para o ensino da Química. Visto que, a TP apresenta uma riqueza de informações e atua como um instrumento facilitador na compreensão de diversos conceitos químicos. Simultaneamente, atende às expectativas dos professores, voltado para complementar a prática docente, frente às fragilidades no ensino da tabela periódica.

\section{CONSIDERAÇÕES FINAIS}

A partir dos argumentos externados pelos professores entrevistados, conforme o questionário disponibilizado na segunda etapa de análise, a fim de verificar as potencialidades do objeto educacional elaborado na etapa intermediária, foi notória a importância desse produto (e-book) não só para o ensino da tabela periódica, mas também, para o ensino da Química, voltando-se para complementar a sua prática frente às fragilidades no ensino desse conteúdo, visto que a TP apresenta uma riqueza de informações e atua como um instrumento facilitador na compreensão de diversos conceitos químicos.

Vale ressaltar que, o material desenvolvido (e-book) é direcionado para professores e alunos do ensino médio, com o intuito de ser um recurso didático complementar e de fácil acesso, por meio digital ou impresso (fichário) que possa ser utilizado sem a pretensão de substituir os livros didáticos e buscando otimizar o tempo, visto que são 2 aulas semanais na rede pública de ensino. Por fim, mediante os resultados dessa investigação, esse objeto educacional se configura como uma proposta diferenciada que vai ao encontro das necessidades [formativas] de docentes e alunos no ensino de Química. 


\section{Educação Química}

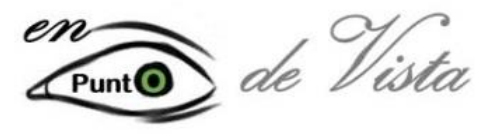

Portanto, torna-se desejo desse trabalho que o material seja amplamente conhecido nas escolas de educação básica, contribuindo para a ressignificação do ensinar, em particular, no que tange ao conteúdo da tabela periódica.

\section{REFERÊNCIAS}

BERBAUM, L. C. M; MALDANER, O. A. M. Estratégias de ensino do conteúdo tabela periódica e sua relação com a aprendizagem conceitual em aulas de química. In: XVII JORNADA DE EXTENSÃO, 2016. Anais... ljuí: Unijuí, 2016. p. 1-5.

CUNHA, M. F. A dimensão pedagógica da tabela periódica no ensino de conceitos químicos. 2019. 117 f. Dissertação (Programa de Mestrado Profissional em Química em Rede Nacional) - Instituto de Ciências Exatas, Naturais e Educação, Universidade Federal do Triângulo Mineiro, Uberaba, 2019.

FERREIRA, L. H; CORREA, K; DUTRA, J. Análise das estratégias de ensino utilizadas para o ensino da tabela periódica. Revista Química Nova na Escola, v. 38, n. 4, p. 349-359, 2016.

KOTZ, J. C.; TREICHEL, P. M.; WEAVER, G. C. Química geral e reações químicas. 6. ed., v. 1, São Paulo: Cengage Learning, 2012.

LEITE, C. E. C et al. SQUID: sistema químico de interatividade e didática. In: 10 ENCONTRO LATINO AMERICANO DE INICIAÇÃO CIENTÍFICA; 6 ENCONTRO LATINO AMERICANO DE PÓS-GRADUAÇÃO, 2006. Anais... São José dos Campos, 2006.

LEITE, H. S. A.; PORTO, P. A. Análise da abordagem histórica para a tabela periódica em livros de Química Geral para o ensino superior usados no Brasil, no século XX. Revista Química Nova, v. 38, n. 4, p. 580-587, 2015.

PENTEADO, M. M.; OLIVEIRA, A.; ZACHARIAS, F. S. TABELIX: jogo da memória como recurso pedagógico para o ensino-aprendizagem sobre a tabela periódica. Revista Ciência e Ideias, v. 2, n. 1, p. 1-9, 2010.

STRATHERN P. O sonho de Mendeleiev: a verdadeira história da química. Tradução, Maria Luiza X. de A. Borges, 1. ed., Rio de Janeiro: Zahar, 2002. 268 p.

TRASSI, R. C. M. et al. Tabela periódica interativa: “um estímulo à compreensão". Acta Scientiarum, v. 23, n. 6, p. 1335-1339, 2001.

UNESCO. 2019 - Ano Internacional da Tabela Periódica dos Elementos Químicos. Disponível em: <http://www.unesco.org/new/pt/brasilia/about-this-office/prizes-and-celebrations/2019-international-yearof-the-periodic-table-of-chemical-elements/> Acesso em: 24 jun. 2019. 


\section{APÊNDICE 1}

\section{Roteiro de entrevista semiestruturada - 1a Etapa}

1) Na sua opinião, qual a importância de se ensinar tabela periódica no ensino médio?

2) De que maneira você aborda os conteúdos da tabela periódica?

3) Em suas aulas, você discute outras representações da tabela periódica?
Sim:
Não: Por quê?

4) Como você aborda a lógica de organização da tabela periódica em suas aulas?

5) De que maneira você explora a história da ciência quando aborda o conteúdo da tabela periódica?

6) Como você relaciona a tabela periódica com os demais conteúdos da química?

\section{APÊNDICE 2 \\ Questionário - 2a ETAPA}

1) Como você qualifica as informações e o conteúdo químico do material educacional elaborado?

2) Você utilizaria o material desenvolvido em suas aulas? (Caso ache pertinente, assinale mais de uma opção):

(a) Sim, pela abrangência de conteúdo e organização objetiva do material.

(b) Sim, pois acredito que despertaria interesse nos alunos.

(c) Sim, pois há carência de materiais com essa perspectiva.

(d) Sim, uma vez que complementa os livros didáticos.

(e) Não, pois não permite uma interpretação da tabela.

(f) Não, pois o conteúdo é superficial.

(g) Não, pois o material é confuso.

(h) Não, pois a linguagem está inadequada.

3) Dentre os conteúdos abordados, qual mais Ihe chamou a atenção? Por quê?

4) Na sua opinião, qual a principal potencialidade (aspecto positivo) do material?

5) Considerando algum aspecto negativo, o que você mudaria ou acrescentaria no material?

6) Como você identifica o conteúdo histórico do material quanto aos (precursores, a contribuição de José Bonifácio e as Mulheres na Ciência)?

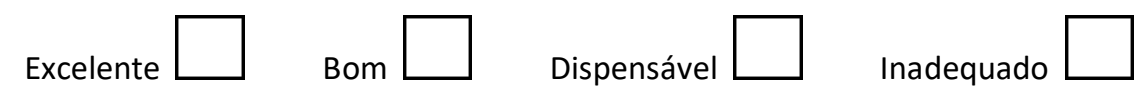

7) Na sua concepção, como o material desenvolvido pode contribuir em suas aulas, assim como, no ensino dos conteúdos químicos? 


\section{Educação Química}

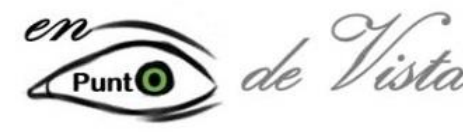

Chemical Education in Point of View

https://revistas.unila.edu.br/eqpv

\section{RESUMO}

Este artigo apresenta um estudo que investigou as potencialidades de uma proposta didático-pedagógica ( $e$ book) destinada aos professores de Química e alunos do ensino médio, a qual foi elaborada e desenvolvida com o objetivo de ser versátil e que promova, a partir de uma linguagem fluída, uma interlocução com os leitores, de modo que, estes possam explorar os conceitos químicos que versam o conteúdo da tabela periódica. É importante salientar que não há a pretensão de substituir os livros didáticos, mas sim, ser um recurso didático complementar e de fácil acesso, por meio digital ou impresso (fichário).

\section{RESUMEN}

Este artículo presenta un estudio que investigó el potencial de una propuesta didáctico-pedagógica (libro electrónico) para profesores de química y estudiantes de secundaria, que fue diseñado y desarrollado con el objetivo de ser versátil y que promueva, desde un lenguaje fluido, una interlocución con los lectores, para que puedan explorar los conceptos químicos que tratan con el contenido de la tabla periódica. Es importante tener en cuenta que no hay intención de reemplazar los libros de texto, sino más bien ser un recurso educativo complementario y de fácil acceso, a través de medios digitales o impresos (carpeta). 